\title{
STRESS: PERSONAL MATTER OR FAMILY AFFAIR? INTRA- AND INTER-INDIVIDUAL RELATIONSHIPS BETWEEN STRESS, PHYSICAL ACTIVITY, SEDENTARY BEHAVIOR, AND NUTRITION
}

\author{
Miriam Reiner, Christina Niermann, Fabian Krapf, and Alexander Woll
}

\begin{abstract}
Individual health behavior, which is determined by individual motives, emotions, and cognitive processes, is embedded in a social environment. One of the most important social environments is the family. According to Family Reciprocal Determinism, stress perceived by one family member becomes part of the family environment and may affect interactions within the family, as well as the health behavior of all family members. This study investigated 214 families, each represented by a mother, a father, and one of their children. The aim of the study was to examine intra- and inter-individual relationships between perceived stress and three health behaviors: physical activity, leisure-time sedentary behavior, and food consumption. The results indicate that individually perceived stress is related to individual health behavior as well as the health behavior of other family members. However, these relationships vary among family members. The inter-individual analyses revealed that this effect is strongest for the relationship of mothers' stress to other family members' health behavior. Investigating the link between perceived stress and health behavior from a family perspective may be useful for understanding the relationship between stress and health.
\end{abstract}

Keywords: family, stress, health behavior, physical activity, leisure-time sedentary behavior, nutrition

Acknowledgments: We thank PD Dr. habil Annegret Mündermann and Sven Henrich for their writing assistance, Matthias Rabel and Lukas Bernhart for their help in data collection, and James Belsey for proofreading this manuscript. We acknowledge support by the German Research Foundation (Deutsche Forschungsgesellschaft) and Open Access Publishing Fund of the Karlsruhe Institute of Technology. The authors declare no conflict of interest. 
International Journal of Child, Youth and Family Studies (2015) 6(1): 68-92

Miriam Reiner, Ph.D. (the corresponding author) is a Scientific Researcher at the Department of Sport and Exercise Science, University of Stuttgart, Allmandring 28, 70569 Stuttgart, Germany. Telephone: +49 71168563168.

E-mail: Miriam.Reiner@inspo.uni-stuttgart.de

Christina Niermann, Ph.D. is a Scientific Researcher at the Department of Sports and Sports Science, Karlsruhe Institute of Technology, Engler-Bunte Ring 15, 76131 Karlsruhe, Germany. E-mail: Christina.Niermann@kit.edu

Fabian Krapf is a Ph.D. candidate and Research Associate at the Department of Teachers Education, University of Konstanz, Universitätsstraße 10, 78457 Konstanz, Germany. E-mail: Fabian.krapf@uni-konstanz.de

Alexander Woll, Prof. Ph.D.. is head of the Department of Sports and Sports Science, Karlsruhe Institute of Technology, Engler-Bunte Ring 15, 76131 Karlsruhe, Germany. E-mail: Alexander.Woll@kit.edu 
Health behavior is determined by personal factors such as motivation, cognition, and emotion. Furthermore, perceived stress is assumed to affect individual health behaviors, such as everyday dietary intake and physical activity (Laugero, Falcon, \& Tucker, 2011).

Perceived stress is presumably related to unhealthy behavior. For instance, stressful situations may lead to lower levels of physical activity, more time spent on sedentary behavior, and unhealthy nutrition (Mouchacca, Abbott, \& Ball, 2013). However, with regard to physical activity, results cited in the literature are inconsistent (Stults-Kolehmainen \& Sinha, 2014).

According to Bandura's social cognitive theory (SCT), individual behavior, like perceptions, emotions, and motivation, emerges through the reciprocal interactions between person, behavior, and environment (Bandura, 1989). Therefore, perceived stress, which arises from interactions between personal, behavioral, and environmental factors, could affect individual physical activity and leisure-time sedentary behavior (going jogging versus watching TV), food choice (eating fresh cooked meals versus eating fast food), and the individual's environment (no fruit for the entire family because of lack of time for grocery shopping) (Bauer, Hearst, Escoto, Berge, \& Neumarck-Sztainer, 2012; Campbell \& Crawford, 2001; Reis, Collins, \& Berscheid, 2000; Repetti, Wang, \& Saxbe, 2009). Also, reciprocal determinism implies that the individual and his or her behavior are affected by the environment and by other persons within this environment (Baranowski, 1997; Taylor, Baranowski, \& Sallis, 1994).

The family is a person's most important social context, with close, intensive, and long lasting interactions (Taylor et al., 1994). The purpose of this study is first, to examine how perceived stress is related to a person's health behaviors, particularly physical activity, leisure-time sedentary behavior, and food choice; and, second, to examine how the perceived stress of one family member is related to the health behavior of other family members.

\section{Family Reciprocal Determinism}

Bandura's concept of a triadic reciprocal determinism (Bandura, 1989) can be expanded to the family level, referring to the model of family reciprocal determinism (Baranowski, 1997). According to this theoretical framework, the individuals, with their specific attributes, that is, their cognitions, motives, and behavior, interact with each other continually over a long time period. The individuals and their interactions are part of a shared family environment; therefore, the family consists of individuals and the higher-level family environment. All family members influence this environment with their individual attributes and in turn, while they are living in the family environment and interacting with each other, they are influenced by these interactions and the environment.

Extending the SCT to the family level offers a new perspective on the link between stress and health behavior. For instance, a person's perception of stress may not only affect his or her own health behavior but also the family environment and through close reciprocal interactions the health behavior of other family members (McAlister, Perry, \& Parcel, 2008). Consequently, a person's health behavior is affected not only by his or her own perceived stress but also by the perceived stress of other family members. According to the model of family reciprocal determinism, two factors could be considered: (a) direct influences through face-to-face interactions between the family members, and (b) indirect influences via the family environment (Baranowski, 1997; Baranowski, Perry, \& Parcel, 1996; Westman \& 
Etzion, 2005). In the latter case, a family member who experiences stress can affect and alter the shared family environment, which in turn affects other family members. An example of a direct influence on health behavior would be a decrease in children's physical activity when parents are too busy to take the children to activity lessons (Bevan \& Reilly, 2011). A change in the shared environment, such as lack of healthy food because of insufficient time for grocery shopping, would be an indirect influence on health behavior. (Bauer et al., 2012; Campbell \& Crawford, 2001; Reis et al., 2000; Repetti et al., 2009).

\section{Correlates of Stress: Individual physical activity, sedentary behavior, and nutrition}

According to SCT, perceived stress and health behavior are connected on the intrapersonal level. A recent review (Stults-Kolehmainen \& Sinha, 2014) has identified inconsistencies regarding the effect of perceived stress on physical activity. For individuals reporting stress, 123 studies showed a reduction in physical activity, 29 studies an increase in physical activity, and 34 studies no relationship or conflicting results regarding physical activity. These inconsistencies may be explained by the fact that, for some people, stress and a lack of time lead to less physical activity, while others use physical activity as a coping strategy for managing stressful situations and regenerating lost resources.

Higher perceived stress has been related to more time spent on sedentary behavior, especially on watching TV (Johansson, Johnson, \& Hall, 1991; Laugero et al., 2011; Wijndaele et al., 2007). However, to date the reason for this phenomenon is largely unknown. Laugero et al. (2011) suggested that stress may reduce the desire for physical activity and thus increase the likelihood of sedentary behavior.

Healthy nutrition in relation to perceived stress can be described in terms of the choice between core foods (essential foods) and non-core foods (superfluous foods) (Johnson, van Jaarsveld, \& Wardle, 2011). Higher perceived stress has been associated with less frequent consumption of core foods and more frequent consumption of non-core foods (Bauer, Neumark-Sztainer, Fulkerson, Hannan, \& Story, 2011; Kandiah, Yake, Jones, \& Meyer, 2006; Oliver \& Wardle, 1999; Wardle, Steptoe, Oliver, \& Lipsey, 2000). Possible explanations for these findings include the fact that time pressure may lead to changes in meal-preparation routines and that consuming a mostly non-core takeout meal saves time (Bevan \& Reilly, 2011). Moreover, perceived stress may lead to reduced self-control with regard to food choices and food quantities, which will tend to promote a higher consumption of non-core foods (Groesz et al., 2011; Torres \& Nowson, 2007).

\section{Correlates of Stress: The physical activity, sedentary behavior, and nutrition of others}

Perceived stress has been shown to affect environmental aspects related to health behavior, such as the family food environment (Bauer et al., 2012). Bevan and Reilly (2011) conducted qualitative interviews with 17 mothers during an eight-month period to capture their perceptions of daily challenges regarding the nutritional and physical activity practices of their children. Stress caused by lack of time resulted in the use of fast food for family meals and a restricted engagement in children's physical activity (e.g., driving to lessons); stress caused by the financial situation of the family resulted in a limited budget for physical activities and healthy nutrition; and stress caused by the perceived safety of the children resulted in restricted activities outside the home. Hence, the perceived stress of one family member appears to affect the health behavior of other family members. However, to the best 
of our knowledge, no other studies are available that take an inter-personal approach with direct relationships between the family members, and hence the inter-individual influences between the perceived stress of one family member and the health behavior of other family members are still largely unknown.

While the theoretical framework of Family Reciprocal Determinism postulates reciprocal interactions between individuals, their behavior, and their environment, the presented empirical results are based on the assumption that perceived stress affects health behavior. Therefore, perceived stress is explored in this study as a predictor variable for individual health behavior, as well as for the health behavior of other family members.

\section{The Present Study}

We propose that including the family context in the concept of a triadic reciprocal determinism between person, behavior, and environment (Bandura, 1989) will increase the understanding of the interrelationship between stress and health behavior. Figure 1 illustrates these presumed reciprocal interactions within the family environment according to SCT. The health behaviors shown for each family member are physical activity, sedentary behavior, and nutrition.

The objective of this study was to research in an explorative way the intra-individual and the inter-individual interactions between perceived stress and health behavior within the family. Based on the reviewed literature, we hypothesized: (a) that stress perceived by an individual affects his or her health behaviors: in particular, physical activity, leisure-time sedentary behavior, and the consumption of core and non-core foods; and (b) that stress perceived by one family member affects the health behavior of other family members. 


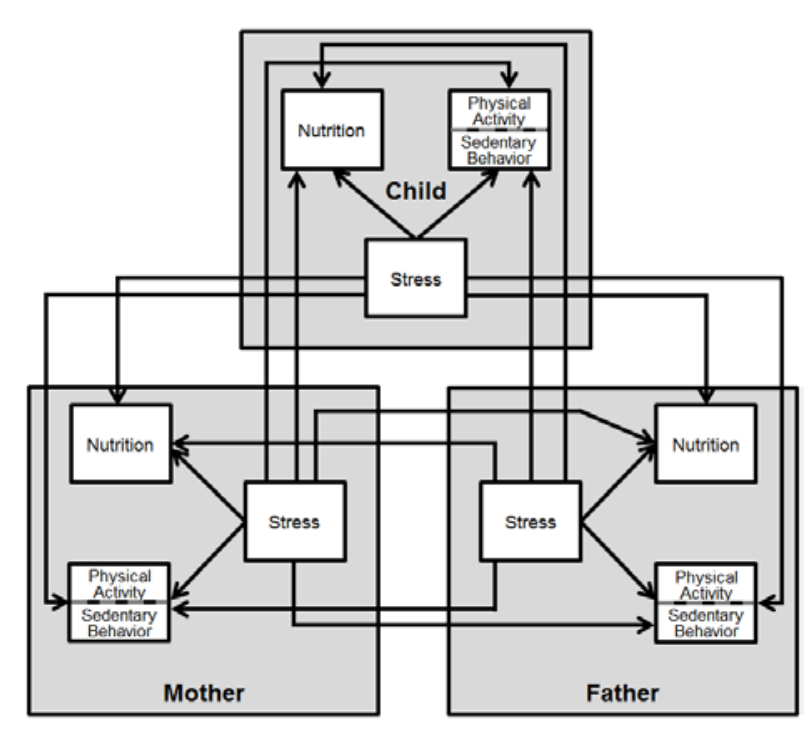

Figure 1a. Schematic illustration of intraindividual (grey boxes) and inter-individual (arrows between family members) effects between perceived stress and health behavior, according to social cognitive theory (SCT).

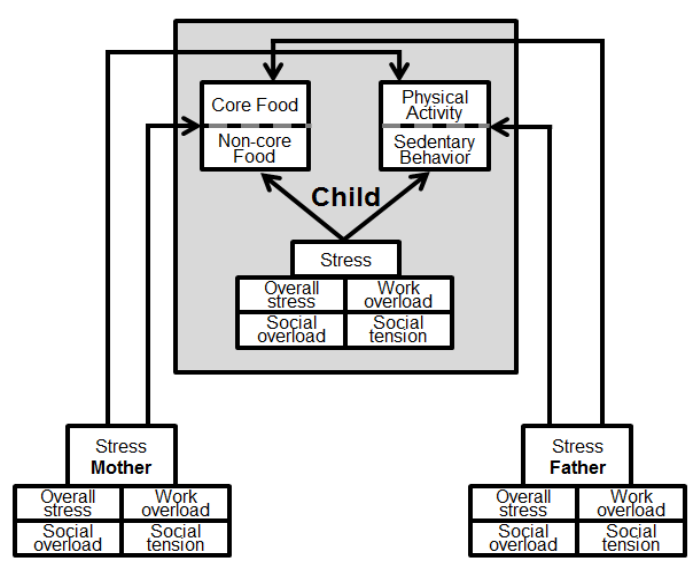

Figure $1 b$. Schematic illustration of the intra-individual (grey box) and the interindividual (arrows between the family members) effects of perceived stress of other family members on the health behavior of the child, with examples.

\section{Data Source}

\section{Methods}

This study was conducted as a part of the multidisciplinary project "EATMOTIVE" funded by the German Federal Ministry of Education and Research. Students of 11 German secondary schools and their parents were invited to join the study. Members of the research team visited the students in their classes. The students were given a short introduction on the background and aims of the study. Furthermore, they received a set of three questionnaires, one for themselves as well as two for their parents. Additionally, the students were told that each of the family members should fill out the questionnaires by themselves. Other than the child who was visited during class, and his or her parents, no other family members were considered for the survey. Of the 319 families who returned the questionnaires, all 214 twoparent families with complete sets of questionnaires were included in this study (Table 1). The excluded families either were single-parent families $(n=50)$ or did not return questionnaires for all three family members $(n=55)$.

Written informed consent was obtained from the parents of the participating children. Participants were given detailed instructions at the distribution of the questionnaires according to the ethics guidelines of the German Psychological Society (Deutsche Gesellschaft für Psychologie \& Berufsverband Deutscher Psychologinnen und Psychologen, 2005). The study protocol was agreed on by a multidisciplinary expert panel of scientists involved in the EATMOTIVE Project. The study conformed to the Declaration of Helsinki 
and the ethics guidelines of the German Psychological Society. All data were analyzed anonymously.

\section{Measures}

Perceived stress. Three subscales of the reliable and valid Trierer Inventory for Chronic Stress (TICS) (Petrowski, Paul, Albani, \& Brähler, 2012; Schulz, Schlotz, \& Becker, 2004) were used for assessing different sources of stress for parents within the preceding three months. The applied subscales were: work overload, social overload, and social tension. Work overload was assessed with eight items capturing stressful situations at work, for example, "I have too many tasks to perform"; social overload was assessed with six items referring to social worries and demands, for example, "I must frequently care for the wellbeing of others"; and social tension was assessed with six items relating to the perception of social conflict, for example, "I have unnecessary conflicts with others". All three subscale scores were summed to a total stress score of perceived chronic stress (Table 1).

The Chronic Stress During Childhood scale (“Chronischer Stress im Kindesalter” or CsiK) (Richartz, Hoffmann, \& Sallen, 2009) was used for assessing different sources of stress in children. The applied subscales were: school overload, social tension, and lack of time. School overload was assessed with eight items about perceived difficulties in school, for example, "School is difficult for me"; social tension was assessed with five items about the perception of social pressure due to a certain behavior, for example, "I have conflicts with others because I speak up for myself”; and lack of time was assessed with three items about perceived stress due to time-related stressors, for example, "I have too little time for friends and hobbies". All three subscale scores were summed to a total perceived chronic stress score.

All participants rated all items on a five-point Likert-Scale with respect to how often they had experienced a certain situation within the preceding three months. The ratings were 0 (never), 1 (rarely), 2 (sometimes), 3 (often), and 4 (very often). 
Table 1.

Characteristics of perceived stress

\begin{tabular}{lcccccccc}
\hline \multicolumn{1}{c}{ (Sub)Scale } & $M$ & $S D$ & $\begin{array}{c}\text { Cronbach's } \\
\alpha\end{array}$ & $\begin{array}{c}\text { Reference } \\
\text { value }\end{array}$ & $t$ & $d f$ & $p$ \\
\hline Mother & & & & & & & \\
\hline Overall $^{\mathrm{e}}$ & 35.222 & 12.749 & .93 & & & & & \\
Work overload $^{\mathrm{a}}$ & 16.441 & 6.606 & .93 & 10.000 & 14.163 & 210 & $<.01$ \\
Social tension $^{\mathrm{b}}$ & 6.213 & 3.771 & .88 & 6.000 & .853 & 210 & .392 \\
Social overload $^{\mathrm{b}}$ & 12.558 & 4.868 & .84 & 7.800 & 14.098 & 207 & $<.01$ \\
\hline Father & & & & & & & \\
\hline$\quad$ Overall $^{\mathrm{e}}$ & 35.387 & 12.717 & .92 & & & & \\
Work overload $^{\mathrm{a}}$ & 16.256 & 6.966 & .94 & 9.600 & 15.395 & 210 & $<.01$ \\
Social tension $^{\mathrm{b}}$ & 5.591 & 3.310 & .89 & 6.200 & 2.658 & 207 & $<.01$ \\
Social overload $^{\mathrm{b}}$ & 12.324 & 4.953 & .85 & 7.100 & 15.391 & 210 & .01 \\
\hline Child $_{\quad}$ & & & & & & & \\
\hline Ovverall $^{\mathrm{e}}$ & 19.903 & 7.503 & .72 & & & & \\
School overload $^{\mathrm{a}}$ & 11.559 & 5.688 & .71 & 8.700 & 7.019 & 194 & $<.01$ \\
Social tension $^{\mathrm{c}}$ & 5.901 & 3.296 & .71 & 4.100 & 7.788 & 202 & $<.01$ \\
Lack of time $^{\mathrm{d}}$ & 2.373 & 0.947 & .63 & 2.240 & 2,032 & 208 & .04 \\
\hline
\end{tabular}

Note. $M=$ mean; $S D=$ standard deviation.

${ }^{\mathrm{a}}$ Sum of 8 items. ${ }^{\mathrm{b}}$ Sum of 6 items. ${ }^{\mathrm{c}}$ Sum of 5 items. ${ }^{\mathrm{d}}$ Sum of 3 items. ${ }^{\mathrm{e}}$ No reference values for the sum of subscales of the Trierer Inventory for Chronic Stress.

Physical activity. Physical activity of parents and children was captured using two items. In accordance with a guideline of the World Health Organization (2010), the number of days with at least 30 minutes (parents) or 60 minutes (child) of moderate-to-vigorous physical activity during a normal week and during the last week were recorded, and the mean of both scores was calculated (Prochaska, Sallis, \& Long, 2001). In addition, a modified version of the "Godin Leisure Time Physical Activity Questionnaire" (Godin \& Shephard, 1997) was applied. The total time (minutes per week) spent on light, moderate, and vigorous activities was recorded and divided by seven to calculate the average time (minutes per day) spent on moderate and vigorous physical activity (MVPA). The energy expenditure was calculated from the intensity of the activities by multiplying the weekly frequency of vigorous, moderate, and light activities by the factors nine, five and three, respectively (Godin \& Shephard, 1997). This value, which we call the "Weekly Activity Index", corresponds to the metabolic equivalent of tasks (MET), reflecting the energy expenditure spent on vigorous, moderate, and light activities. The time per week spent on either moderate or vigorous physical activities was combined. These measures of physical activity allow examination of the effects of three dimensions of physical activity: overall frequency during the week, which reflects the extent to which habitual physical activity is part of the individual's lifestyle (Prochaska et al., 2001); time spent on MVPA (Godin \& Shephard, 1997), which is considered very beneficial for health (Dishman, Washburn, \& Heath, 2004); and weekly energy expenditure (Godin \& Shephard, 1997).

Sedentary time. The amount of time spent on leisure-time sedentary activities was assessed by asking parents and children how much of their leisure time they spend on a typical day on the following sedentary activities: watching TV; reading books, magazines, or newspapers; playing games on a computer or games console; spending time on the computer or Internet; and other sedentary activities. Participants provided separate information for 
weekdays and weekends. Mean daily sedentary time was calculated by adding the daily sedentary time for weekdays and weekends and dividing by five days for weekdays and by two days for weekends. The same formula was used to calculate mean media consumption time, which is time spent watching TV, playing games on a computer or games console, or on the computer or Internet.

Food consumption. Mother, father, and child separately completed a Food Frequency Questionnaire (Winkler \& Döring, 1998). On a seven-point Likert scale, ranging from 0 (never) to 6 (several times per day) each participant rated how often specific food items were normally consumed. The answers were recoded to calculate an index representing the frequencies of consumption during the week according to the German Nutrition Society (2013) using the following scale: 0 (never/once per month or less/several times per month); 1 (once per week); 3 (several times per week); 7 (daily); and 14 (several times per day). Ten items of the Food Frequency Questionnaire were selected and the given ratings were summed up to a core food index, which included muesli, salad, fruits, vegetables, dairy products, and fish, and a non-core food index, which included chocolate, sweets, cakes, and salty snacks. The selection of food types was made on the basis of the guidelines of the Australian National Health and Medical Research Council (Cashel \& Jeffreson, 1995). According to these guidelines, core foods comprise types of food that are part of a healthy diet; in contrast, non-core foods reflect an unhealthy diet (Bell, Kremer, Magarey, \& Swinburn, 2005; Johnson et al., 2011).

Educational level. Health behavior is associated with personal educational level (Baum, Garofalo, \& Yali, 2006; Cutler \& Lleras-Muney, 2010) and with the educational level of other family members (Chen \& Li, 2009). Therefore, it was necessary to include the personal educational level as a covariate in the analyses of health behavior. Education level was assessed by asking for the highest graduation level. Using the German tripartite school system, the categories ranged from "no qualification" to "university-entrance diploma (Abitur)", and were categorized into "low educational level” (no graduation, or Hauptschule), "medium educational level” (Realschule and lower work-related graduation), and "high educational level” (higher occupation-specific graduation and Gymnasium).

\section{Data Analysis}

Empirical model. Intra-individual effects are defined as the perceived stress of one person and its effect on that individual's health behavior. Inter-individual effects are defined as the perceived stress of one person and its effect on the health behavior of another person. Intra-individual and inter-individual effects were analyzed using multivariate linear regression models. All analyses were controlled for the educational levels of the mother and father by including the educational levels as covariates in the multivariate linear regression models. Statistical analyses were performed in SPSS for Windows version 21.0. Statistically significant results were based on the standardized beta-coefficients of the multivariate linear regression models. The significance levels for all statistical tests were set to .05 $\left(^{*}\right)$ and .01 $(* *)$. Results with $p$-values below $.10\left(^{+}\right)$were interpreted as nearly significant results. 


\section{Perceived Stress}

\section{Results}

The largest stress contributors in children and in parents were school and work overload, respectively (Table 2). Mothers, fathers, and children perceived significantly more stress in all subscales than the reference group, as shown in Table 1 (Petrowski et al., 2012; Richartz et al., 2009). Children with lower educational levels reported more overall stress and stress due to school overload and lack of time than children with medium or high educational levels. Our findings were:

- Overall stress: $M_{\text {low }}=24.7 ; S D_{\text {low }}=8.1 ; M_{\text {medium }}=21.3 ; S D_{\text {medium }}=7.2 ; M_{\text {high }}=$ $19.2 ; S D_{\text {high }}=7.1 ; F_{(2,175)}=5.8 ; p<.001$;

- Stress due to school overload: $M_{\text {low }}=14.6 ; S D_{\text {low }}=5.5 ; M_{\text {medium }}=13.1 ; S D_{\text {medium }}$ $=6.0 ; \mathrm{M}_{\text {high }}=11.1 ; S D_{\text {high }}=5.4 ; \mathrm{F}_{(2,179)}=5.1 ; p<.001 ;$

- $\quad$ Stress due to lack of time: $M_{\text {low }}=2.5 ; S D_{\text {low }}=1.2 ; M_{\text {medium }}=2.0 ; S D_{\text {medium }}=1.0$; $\left.M_{\text {high }}=2.4 ; S D_{\text {high }}=0.9 ; F_{(2,192)}=3.1 ; p=.053\right)$.

\section{Health Behavior}

As seen in Table 2, only $7.5 \%$ of the children, $20.1 \%$ of the fathers, and $22.3 \%$ of the mothers met the WHO guidelines of at least 30 minutes activity per day for adults and at least 60 minutes activity per day for children on at least most days during the week (World Health Organization, 2010). Children spent 45 minutes, mothers 31 minutes, and fathers 36 minutes on MVPA (Table 2). Children spent approximately five hours per day on sedentary activities after school on weekdays and at least seven and a half hours per day on the weekend. Media consumption (TV, PC, Internet, and games consoles) accounted for the largest amount of sedentary activity. These sedentary times are in accord with the German subsample of the Health Behavior in School-aged Children Study 2009/2010 (HBSC Team Germany, 2011a, 2011b; Kolip, Klocke, Melzer, \& Ravens-Sieberer, 2013). In contrast, parents spent about three hours per day on sedentary activities on weekdays and four hours per day on weekends. Time spent with media consumption was lower for parents than for children; however, fathers spent more time with media than mothers did. Children consumed more non-core foods than their mothers and fathers. However, most families ate non-core foods at least several times a week or even daily.

Health behaviors, especially time spent on sedentary activities, were associated with educational level: persons with higher educational levels had slightly healthier behaviors, with more physical activity, less sedentary time, and more frequent consumption of core foods (data not shown). 
Table 2.

Descriptive statistics ( $M$ and SD) of the subject characteristics.

\begin{tabular}{|c|c|c|c|c|c|c|c|}
\hline \multirow[t]{2}{*}{ Category } & \multirow[t]{2}{*}{ Subcategory } & \multicolumn{2}{|c|}{ Child } & \multicolumn{2}{|c|}{ Mother } & \multicolumn{2}{|c|}{ Father } \\
\hline & & $M$ & $S D$ & $M$ & $S D$ & $M$ & $S D$ \\
\hline \multirow[t]{2}{*}{ Age } & girls $(n=126)$ & 14.1 & 1.4 & 45.0 & 4.4 & 47.7 & 6.9 \\
\hline & boys $(n=85)$ & 14.5 & 1.9 & & & & \\
\hline \multirow[t]{3}{*}{ Educational level } & low & \multicolumn{2}{|c|}{$12.2 \%$} & \multicolumn{2}{|c|}{$17.8 \%$} & \multicolumn{2}{|c|}{$24.4 \%$} \\
\hline & medium & \multicolumn{2}{|c|}{$14.2 \%$} & \multicolumn{2}{|c|}{$41.1 \%$} & \multicolumn{2}{|c|}{$18.8 \%$} \\
\hline & high & \multicolumn{2}{|c|}{$73.6 \%$} & \multicolumn{2}{|c|}{$41.1 \%$} & \multicolumn{2}{|c|}{$56.8 \%$} \\
\hline \multirow[t]{5}{*}{ Working status } & full-time & & & \multicolumn{2}{|c|}{$15.5 \%$} & \multicolumn{2}{|c|}{$89.3 \%$} \\
\hline & part-time & & & \multicolumn{2}{|c|}{$67.6 \%$} & \multicolumn{2}{|c|}{$2.8 \%$} \\
\hline & & & & \multicolumn{2}{|c|}{$M=19.8 \mathrm{~h}$} & \multicolumn{2}{|c|}{$M=22.0 \mathrm{~h}$} \\
\hline & & & & \multicolumn{2}{|c|}{$S D=7.0 \mathrm{~h}$} & \multicolumn{2}{|c|}{$S D=8.1 \mathrm{~h}$} \\
\hline & not working & & & \multicolumn{2}{|c|}{$16.9 \%$} & \multicolumn{2}{|c|}{$7.9 \%$} \\
\hline \multicolumn{8}{|c|}{ Physical activity } \\
\hline \multicolumn{2}{|c|}{$\begin{array}{l}\text { Frequency during the week } \\
\text { (days/week) }\end{array}$} & 3.9 & 1.6 & 4.4 & 2.0 & 4.7 & 2.1 \\
\hline \multicolumn{2}{|c|}{ Time with MVPA (min/day) } & 45.1 & 31.8 & 31.1 & 29.9 & 36.2 & 48.4 \\
\hline \multicolumn{2}{|c|}{ Weekly Activity Index (MET) } & 51.1 & 26.1 & 44.9 & 24.2 & 45.3 & 25.5 \\
\hline \multicolumn{8}{|c|}{ Leisure-time sedentary behavior (min/day) } \\
\hline \multicolumn{2}{|c|}{$\begin{array}{l}\text { Time with sedentary behavior - } \\
\text { weekday }\end{array}$} & 297.9 & 216.3 & 184.2 & 120.6 & 187.6 & 116.8 \\
\hline $\begin{array}{l}\text { Time with sed } \\
\text { weekend }\end{array}$ & ntary behavior - & 450.7 & 369.5 & 239.6 & 142.1 & 252.4 & 137.5 \\
\hline Media consun & ption - weekday & 174.8 & 164.4 & 109.9 & 111.2 & 120.3 & 105.9 \\
\hline Media consun & ption - weekend & 276.8 & 316.1 & 133.8 & 117.7 & 157.6 & 108.0 \\
\hline Nutrition (averag & servings/day) & & & & & & \\
\hline Core foods & & 17.1 & 9.2 & 19.0 & 8.2 & 15.2 & 8.3 \\
\hline Non-core fooc & & 9.6 & 9.7 & 7.1 & 7.2 & 7.5 & 7.6 \\
\hline
\end{tabular}

Note. For physical activity: frequency during the week (days/week), the range is 0-7 days. Media consumption is minutes per day spent on TV, PC/Internet, or computer/console games. Core foods are salad, vegetables, fruit, muesli, dairy, and fish; non-core foods are chocolate, cake, salty snacks, and sweets. $M=$ mean; $S D=$ standard deviation.

\section{Intra-individual effects of perceived stress on physical activity, sedentary behavior, and nutrition}

Children. In children, physical activity was not related to overall perceived stress (Table 3). However, children spent less time on moderate-to-vigorous activities if they were stressed due to school overload (Table 4). More overall stress went along with more time spent on sedentary activities and media on weekdays (Table 3). While higher stress due to school overload was associated with higher media consumption on weekdays, stress due to lack of time reduced the time spent with sedentary activities and media consumption on weekends (Table 4). The perceived stress of children was not related to the consumption of core and non-core foods (Table 3, Table 4). 
Mothers. Overall, perceived stress of mothers did not affect their physical activity behavior or their consumption of core and non-core foods (Table 3, Table 4). However, if the mother was more stressed due to work overload and social tension, she consumed core foods less frequently. In contrast, in the case of stress due to work overload, she consumed non-core foods more frequently, but when she was stressed due to social tension, she ate core foods less frequently (Table 4).

Fathers. Perceived stress was not associated with physical activity; however, the father spent less time on sedentary behavior on weekdays when he was stressed due to work overload (Table 4). As with the results for mothers, the father consumed less core foods if he was stressed due to work overload; however, he did not consume more non-core foods. He consumed non-core foods more often if he was stressed due to social overload (Table 4).

\section{Inter-individual effects of perceived stress on physical activity, sedentary behavior, and nutrition}

Child. The child was less frequently physically active and had a lower weekly activity index if the mother perceived higher overall stress (Table 3) and more stress due to work overload (Table 4). In contrast, only higher stress due to work overload of the father was associated with more frequent physical activity of the child (Table 4). Moreover, the child spent more time on sedentary behavior on weekdays if the mother was stressed due to social overload. The more overall stress the mother perceived, the less core foods and the more noncore foods the child consumed (Table 3).

Mother. Perceived stress of the child and the father did not significantly affect the physical activity or the nutrition of the mother. The more stress overall (Table 3) and stress due to school overload (Table 4) the child perceived, the more time the mother spent on sedentary behavior on weekdays and weekends. In contrast, higher perceived stress overall (Table 3) and stress due to work overload (Table 4) of the father went along with the mother's lower sedentary time on weekends and lower media consumption on weekdays and weekends.

Father. Perceived stress of the child and the mother did not significantly affect physical activity of the father. However, the father spent more time on sedentary behavior and with media on weekdays and weekends if the child was stressed overall (Table 3) and stressed due to school overload (Table 4). In contrast, when the mother perceived more stress due to social tension, the father spent less time with media on weekdays (Table 4). Moreover, higher perceived overall stress (Table 3) and stress due to work overload (Table 4) of the mother was associated with lower consumption of core foods by the father. 
Table 3.

Effects of perceived stress (overall) on health behaviors-multivariate linear regression analyses

\begin{tabular}{|c|c|c|c|c|c|c|}
\hline \multirow[t]{2}{*}{ Variable } & \multirow[t]{2}{*}{ Person } & \multicolumn{3}{|c|}{ Overall perceived stress } & \multicolumn{2}{|c|}{ Model values } \\
\hline & & Child & Mother & Father & $F$ & $R^{2}$ \\
\hline \multicolumn{7}{|l|}{ Physical activity } \\
\hline \multirow{3}{*}{$\begin{array}{l}\text { Frequency during the week } \\
\text { (days/week) }\end{array}$} & Child & -.066 & $-.256 * *$ & .094 & $2.371^{*}$ & .042 \\
\hline & Mother & -.034 & .001 & .149 & .861 & .026 \\
\hline & Father & -.060 & -.010 & -.132 & .755 & .023 \\
\hline \multirow[t]{3}{*}{ Time with MVPA (min/day) } & Child & -.023 & -.133 & .131 & 1.273 & .009 \\
\hline & Mother & .024 & -.141 & .085 & .622 & .026 \\
\hline & Father & -.074 & -.009 & .097 & 1.014 & .040 \\
\hline \multirow[t]{3}{*}{ Weekly Activity Index (MET) } & Child & .002 & $-.259 * *$ & .057 & 1.991 & .037 \\
\hline & Mother & -.015 & -.001 & .011 & .196 & .009 \\
\hline & Father & -.089 & .059 & -.032 & .253 & .012 \\
\hline \multicolumn{7}{|c|}{ Leisure-time sedentary behavior (min/day) } \\
\hline \multirow{3}{*}{$\begin{array}{l}\text { Time with sedentary behavior - } \\
\text { weekday }\end{array}$} & Child & $.181 *$ & $.138^{+}$ & -.005 & $2.822 *$ & .051 \\
\hline & Mother & $.226 * *$ & .056 & -.049 & $2.124^{*}$ & .033 \\
\hline & Father & $.246 * *$ & -.031 & -.120 & $6.363^{* *}$ & .137 \\
\hline \multirow{3}{*}{$\begin{array}{l}\text { Time with sedentary behavior - } \\
\text { weekend }\end{array}$} & Child & .040 & .019 & .011 & .853 & .025 \\
\hline & Mother & $.212 * *$ & .001 & $-.117^{+}$ & $2.282 *$ & .037 \\
\hline & Father & $.164 *$ & -.023 & -.041 & $3.531 * *$ & .070 \\
\hline \multirow[t]{3}{*}{ Media consumption - weekday } & Child & $.158 *$ & .102 & .022 & $2.991^{*}$ & .056 \\
\hline & Mother & $.149^{+}$ & .106 & $-.127 *$ & 1.744 & .022 \\
\hline & Father & $.295^{* *}$ & -.009 & -.054 & $6.901 * *$ & .149 \\
\hline \multirow[t]{3}{*}{ Media consumption - weekend } & Child & -.012 & -.047 & .034 & 1.792 & .023 \\
\hline & Mother & $.154^{+}$ & .128 & $-.163^{*}$ & $2.525 *$ & .043 \\
\hline & Father & $.189 * *$ & -.001 & -.040 & $5.093 * *$ & .108 \\
\hline \multicolumn{7}{|c|}{ Nutrition (average servings/week) } \\
\hline \multirow[t]{3}{*}{ Core foods } & Child & -.034 & $-.135 *$ & -.007 & 1.571 & .017 \\
\hline & Mother & -.079 & -.118 & .085 & $4.110 * *$ & .086 \\
\hline & Father & -.001 & $-.194 *$ & -.012 & 2.053 & .031 \\
\hline \multirow[t]{3}{*}{ Non-core foods } & Child & .097 & $.131^{+}$ & -.029 & 1.031 & .031 \\
\hline & Mother & .025 & .072 & -.023 & .604 & .012 \\
\hline & Father & .019 & -.080 & .084 & 1.765 & .022 \\
\hline
\end{tabular}

Note. Standardized beta coefficients; significance levels: ${ }^{+} p<.10{ }^{*} p<.05 ;{ }^{* *} p<.01$; model values: $d f=6$; covariate: all results were controlled for personal educational levels of mothers and fathers. 
International Journal of Child, Youth and Family Studies (2015) 6(1): 68-92

Table 4.

Effects of perceived stress (different sources of stress) on health behaviors-multivariate linear regression analyses

\begin{tabular}{|c|c|c|c|c|c|c|c|c|c|c|c|c|}
\hline \multirow{3}{*}{2} & \multirow[t]{3}{*}{ Person } & \multicolumn{3}{|c|}{ Child } & \multicolumn{3}{|c|}{ Mother } & \multicolumn{3}{|c|}{ Father } & \multicolumn{2}{|l|}{$\begin{array}{l}\text { Model } \\
\text { values }\end{array}$} \\
\hline & & \multicolumn{2}{|c|}{$\begin{array}{l}\text { Schoo Social } \\
\text { l over- tensio }\end{array}$} & $\begin{array}{l}\text { Lack } \\
\text { of }\end{array}$ & $\begin{array}{l}\text { Work } \\
\text { over- }\end{array}$ & $\begin{array}{l}\text { Social } \\
\text { over- }\end{array}$ & $\begin{array}{l}\text { Social } \\
\text { tensio }\end{array}$ & $\begin{array}{l}\text { Work } \\
\text { over- }\end{array}$ & $\begin{array}{l}\text { Social } \\
\text { over- }\end{array}$ & $\begin{array}{l}\text { Social } \\
\text { tensio }\end{array}$ & $F$ & $R^{2}$ \\
\hline & & load & $\mathrm{n}$ & time & load & load & & & load & & & \\
\hline \multicolumn{13}{|l|}{ Physical activity } \\
\hline \multirow{3}{*}{$\begin{array}{l}\text { Frequency during } \\
\text { the week } \\
\text { (days/week) }\end{array}$} & Child & -.068 & .023 & .001 & $-.223^{*}$ & -.068 & .026 & $.218 *$ & -.127 & -.026 & 1.286 & .019 \\
\hline & Mother & .049 & -.099 & .131 & -.171 & .149 & .088 & .157 & -.078 & .088 & 1.291 & .018 \\
\hline & Father & -.127 & .081 & $228 * *$ & -.003 & .031 & .019 & -.120 & .021 & -.021 & 1.327 & .021 \\
\hline \multirow{3}{*}{$\begin{array}{l}\text { Time with MVPA } \\
\text { (min/day) }\end{array}$} & Child & $-.102 *$ & .107 & -.045 & $-.137^{+}$ & -.014 & -.066 & .112 & -.072 & .153 & 1.142 & .010 \\
\hline & Mother & .034 & -.017 & .005 & .126 & -.143 & $-.184^{+}$ & -.165 & $.247^{+}$ & .057 & .809 & .074 \\
\hline & Father & -.045 & -.003 & .127 & -.042 & .070 & -.013 & .202 & -.090 & .028 & .819 & .070 \\
\hline \multirow{3}{*}{$\begin{array}{l}\text { Weekly Activity } \\
\text { Index (MET) }\end{array}$} & Child & -.045 & .080 & -.034 & $-.300 *$ & .026 & -.019 & .140 & -.078 & -.019 & 1.118 & .010 \\
\hline & Mot & -.067 & .047 & -.075 & -.176 & .190 & -.035 & -.063 & .088 & -.049 & .3773 & .039 \\
\hline & Father & -.156 & .104 & .053 & -.054 & -.008 & .134 & .123 & -.130 & -.041 & .445 & .04 \\
\hline \multicolumn{13}{|c|}{ Leisure-time sedentary behavior (min/day) } \\
\hline \multirow{3}{*}{$\begin{array}{l}\text { Time with } \\
\text { sedentary behavior } \\
\text { - weekday }\end{array}$} & Child & .134 & .098 & .003 & .023 & $.241 *$ & -.124 & -.019 & .014 & -.006 & $\begin{array}{c}1.991 \\
*\end{array}$ & .060 \\
\hline & Mother & $\begin{array}{c}.269 * \\
*\end{array}$ & -.029 & -.049 & $-.155^{+}$ & $.189^{+}$ & .021 & -.022 & -.099 & .047 & 1.624 & .039 \\
\hline & Father & $.161^{*}$ & .116 & -.079 & -.015 & .040 & -.116 & $-.240 *$ & .078 & .161 & $\begin{array}{c}3.388 \\
*\end{array}$ & .133 \\
\hline \multirow{3}{*}{$\begin{array}{l}\text { Time with } \\
\text { sedentary behavior } \\
\text { - weekend }\end{array}$} & Chi & .031 & .032 & $-.172 *$ & .058 & .029 & -.122 & .058 & -.073 & .020 & 1.185 & .012 \\
\hline & Mo & $\begin{array}{c}.245^{*} \\
*\end{array}$ & -.020 & $-.147^{+}$ & $-.100^{+}$ & .138 & -.056 & $-.124 *$ & .000 & -.045 & $\begin{array}{c}1.956 \\
*\end{array}$ & .058 \\
\hline & Father & $\begin{array}{c}.215^{*} \\
*\end{array}$ & -.058 & -.075 & -.079 & .088 & -.063 & -.048 & .004 & -.025 & $\begin{array}{c}2.012 \\
*\end{array}$ & .06 \\
\hline \multirow{3}{*}{$\begin{array}{l}\text { Media } \\
\text { consumption - } \\
\text { weekday }\end{array}$} & Child & $.159 *$ & .037 & -.018 & .011 & .151 & -.025 & -.039 & .000 & .053 & 1.717 & .044 \\
\hline & Mother & .139 & .021 & -.015 & -.033 & .103 & .053 & $-.132 *$ & .047 & -.093 & .953 & .061 \\
\hline & Father & $\begin{array}{c}.209^{*} \\
*\end{array}$ & .139 & .019 & -.022 & .150 & $-.198 *$ & -.124 & -.016 & .147 & $\begin{array}{c}3.812 \\
*\end{array}$ & .153 \\
\hline \multirow{3}{*}{$\begin{array}{l}\text { Media } \\
\text { consumption - } \\
\text { weekend }\end{array}$} & Child & .003 & .012 & $-.167 *$ & .055 & -.057 & -.088 & .051 & -.084 & .070 & 1.382 & .024 \\
\hline & Mother & $.152^{+}$ & .012 & -.036 & .043 & .047 & .063 & $-.128 *$ & .035 & -.139 & 1.131 & .02 \\
\hline & Father & $\begin{array}{c}.261 * \\
*\end{array}$ & -.073 & .017 & -.028 & .143 & -.140 & -.084 & -.004 & .059 & $\begin{array}{c}2.991 \\
*\end{array}$ & .11 \\
\hline \multicolumn{13}{|c|}{ ge servings/day) } \\
\hline \multirow[t]{3}{*}{ Core foods } & Child & -.056 & .030 & .084 & .019 & -.104 & -.095 & .116 & -.010 & -.132 & 1.313 & .02 \\
\hline & Mother & -.051 & -.049 & -.016 & $-.243^{*}$ & $.244 *$ & $-.176 *$ & -.101 & $.199^{+}$ & -.006 & $\begin{array}{c}3.071 \\
*\end{array}$ & .11 \\
\hline & Father & -.008 & -.026 & -.024 & $-.263^{*}$ & .116 & -.077 & $-.236 *$ & $.243^{*}$ & -.016 & $\begin{array}{c}1.957 \\
*\end{array}$ & .060 \\
\hline \multirow[t]{3}{*}{ Non-core foods } & Child & -.079 & .256 & .009 & $-.185^{+}$ & $\begin{array}{c}.300^{*} \\
*\end{array}$ & .081 & -.094 & .085 & -.061 & $\begin{array}{c}2.324 \\
*\end{array}$ & .080 \\
\hline & Mother & -.022 & .074 & .020 & $\begin{array}{c}.317^{*} \\
*\end{array}$ & $-.287 *$ & .050 & .174 & -.091 & -.137 & 1.766 & .047 \\
\hline & Father & .026 & -.002 & -.070 & .007 & -.076 & -.043 & .061 & -.025 & .067 & .912 & .059 \\
\hline
\end{tabular}

Note. Standardized beta coefficients; significance levels: ${ }^{+} \mathrm{p}<.10{ }^{*} \mathrm{p}<.05$; ${ }^{* *} \mathrm{p}<.01$; model values: $d f=6$; covariate: all results were controlled for personal educational levels of mothers and fathers. 


\section{Discussion}

The objective of this study was to explore whether individual perceived stress is related to the health behavior of other family members. Based on the model of Family Reciprocal Determinism it was assumed that an individual's perceived stress affects both the interactions with others and the shared family environment and therefore is related to the health behavior of other family members. The results of this study support the assumption that there are intra- as well as inter-individual relationships between perceived stress and health behavior.

\section{Intra-individual effects of perceived stress on physical activity, sedentary behavior, and nutrition}

In agreement with previous studies (Bevan \& Reilly, 2011; Johansson et al., 1991; Michels et al., 2012; Wallis \& Hetherington, 2009; Wardle et al., 2000), perceived stress affected the time spent on sedentary behavior and the consumption of core and non-core foods for all family members. The effects of individually perceived stress on the different health behaviors varied between family members and with regard to the sources of stress. Greater stress due to work overload was associated with less time spent on sedentary activities, and especially on media consumption, for all family members. It has been shown that time spent on sedentary behavior increases the risk of developing obesity, certain coronary heart diseases (Chomistek et al., 2013), and diabetes mellitus Type 2 (Proper, Singh, Van Mechelen, \& Chinapaw, 2011). Greater stress due to work overload is associated with a "positive" health effect, the reduction of sedentary time. This may be caused by longer working hours away from home. In contrast, greater stress due to social overload was associated with slightly more time spent on sedentary activities during weekdays for mothers. Sedentary activities, such as watching TV, have been discussed as a coping strategy for recharging depleted resources (Heikkilä et al., 2013; Park \& Iacocca, 2014). Hence, more time spent on sedentary activities could be a way of coping with stress (Baumeister, Bratslavsky, Muraven, \& Tice, 1998).

Overall, perceived stress was not related to either mothers' or fathers' nutrition, which is not in agreement with results of other studies (Zellner et al., 2006; Zellner, Saito, \& Gonzales, 2007). For instance, Zellner et al. (2006) reported gender differences in the relative consumption of core and non-core foods during and after stressful situations. Dietary restrained eating, which is mostly found in women, plays an important role (Wardle et al., 2004; Zellner et al., 2006). Women, especially those who report being dietary-restrained eaters, presumably react with an overeating of non-core foods during and after stressful situations because of a loss of self-control under stress (Wardle et al., 2004; Zellner et al., 2006). In contrast, men do not seem to change their consumption of core and non-core foods when they perceive stress (Zellner et al., 2007). Considering the different sources of stress shows a more complex picture: For both parents, stress due to work overload was associated with lower consumption of core foods and stress due to social overload was associated with more frequent consumption of core foods. Opposite effects were found for non-core foods: For mothers, higher perceived stress due to work overload was associated with more frequent consumption of non-core foods, whereas stress due to social overload went with less frequent consumption. These relationships may be caused by work overload and longer working hours 
resulting in less time and lower motivation for preparing healthy meals (Bevan \& Reilly, 2011). Other studies have indicated that work stress leads to fewer whole meals and more frequent snacking during working times (Bevan \& Reilly, 2011; Oliver \& Wardle, 1999; Tryon, DeCant, \& Laugero, 2013; Wallis \& Hetherington, 2009).

In our study, perceived overall stress did not affect physical activity in any of the family members, which is in agreement with results of the review by Stults-Kolehmainen and Sinha (2014). In contrast, other studies have indicated that greater perceived stress is related to less time spent on physical activity (Aldana, Sutton, Jacobson, \& Quirk, 1996; Kouvonen et al., 2005; Kouvonen et al., 2013; Laugero et al., 2011; Ng \& Jeffrey, 2003). To date, the mechanism of how specific aspects of individually perceived stress are linked to individual health behaviors is poorly understood. One possible pathway connects depleted individual resources in stressful situations (Muraven \& Baumeister, 2000) with resulting reduced selfcontrol with regard to being physically active or resisting eating non-core foods. Watching TV or consuming non-core foods are activities that require less self-control and may be coping strategies to recharge the individual's resources (Steptoe, 2007). However, physical activity has also been discussed as a possible coping strategy (Azizi, 2011; Balantekin \& Roemmich, 2012; Rostad \& Long, 1996). The standard deviations in parameters describing health behaviors were very large, indicating large individual differences. Reactions to stressful situations presumably vary between persons, and hence it is reasonable that one person uses physical activity as a coping strategy for stress while another person uses leisuretime sedentary behavior as a coping strategy (Azizi, 2011). A similar phenomenon of personspecific changes in eating behavior, either overeating or under-eating, appears during or after stressful situations or periods (Balantekin \& Roemmich, 2012; Oliver \& Wardle, 1999; Roemmich, Lambiase, Lobarinas, \& Balantekin, 2011). Further research integrating individual coping strategies is necessary to clarify the relationship between perceived stress and health behavior. Moreover, the results emphasize the importance of considering different sources of stress.

\section{Inter-individual effects of perceived stress on physical activity, sedentary behavior, and nutrition}

In this study, we also considered how the perceived stress of one family member may affect the health behavior of other family members. Based on the results of this study, three main aspects of this interrelationship could be identified: the important role of the mother, the parent dyad, and the role of the child.

The important role of the mother. Perceived stress of the mother affected the health behavior (especially physical activity and the consumption of core and non-core foods) of the other family members, especially the child. According to the literature, the mother is mostly responsible for health-related behavior within the family: Preparing family meals or going grocery shopping is commonly the duty of mothers (Bevan \& Reilly, 2011; Devine, Connors, Sobal, \& Bisogni, 2003; Tinsley, 1997) and mothers seem to act as guards to protect and advise on healthy living (Beets, Cardinal, \& Alderman, 2010). Currently, this role seems to remain predominantly the mother's, even though mothers now work away from home more often (Bauer et al., 2012; Beagan, Chapman, D'Sylva, \& Bassett, 2008; Jabs et al., 2007; Lake et al., 2006). Hence, individually perceived stress of mothers could affect intra-familial interactions and organizational arrangements in such areas as driving children to activity lessons, going grocery shopping, and preparing meals. Bevan and Reilly (2011) postulated 
that lack of time is one of the most serious barriers mothers have to overcome. It appears likely that mothers, especially if they are working, risk being overwhelmed by the many tasks that must be carried out in order to manage daily family life (Lundberg \& Frankenhaeuser, 1999). The resulting lack of time could be a contributor to the negative association between perceived stress and health behavior within the family. To overcome these problems, a better balance of family and career for working mothers and a more equitable division of responsibilities and housework between the parents seems warranted (Martín-Fernández, de los Ríos, Cazorla, \& Martínez-Falero, 2009).

The parent dyad. The results of our study indicate that the perceived stress of one parent affects the other parent's behavior, especially regarding leisure-time sedentary behavior. For instance, higher perceived stress of the father is associated with less time spent by the mother on sedentary behavior on weekends and with media on weekdays and weekends. Domestic division of housework could be responsible for these effects (Beagan et al., 2008). Perceived stress of fathers mostly correlates with more time spent working away from home and a greater work-family conflict (Adkins \& Premeaux, 2012; Beaujot \& Andersen, 2007). More time spent away from home inhibits an equitable division of housework between the parents. As a result most of the responsibility for family-related tasks falls on one partner (Baxter, 2000). In turn, the mother having to complete more tasks leads to a higher perceived stress, as there is less time for leisure-time sedentary behavior or other stress-relieving activities (Bevan \& Reilly, 2011), which fits the framework of Family Reciprocal Determinism.

The role of the child. Greater perceived overall stress and stress due to school overload of the child was associated with more sedentary behavior of both parents. There are several possible reasons for this relationship. Time spent on sedentary behavior includes time spent on diverse inactive behaviors such as sitting or reading. Hence, a possible reason for the longer time spent on sedentary behavior for the mother could be that she supports the child in doing homework or studying with the child (Hoover-Dempsey et al., 2001). Interestingly, greater perceived stress due to school overload of the child was associated with the father spending more time with media on weekdays and weekends. There is no obvious explanation for this phenomenon, and it is possible that other parameters such as the educational level account for this relationship. Health behaviors and perception of stress were related to the educational levels of the family members. For instance, the descriptive results of this study indicated that the child's perceived stress is related to the type of school attended. The educational level of the child was in turn related to the educational level of the parents: the higher the educational level of the parents, the higher the educational level of the child. Furthermore, the lower the educational level of the person, the more time the person spent on sedentary behavior and with media. Hence, it seems feasible that educational level acts as a moderator of the intra-individual relationship between perceived stress and health behavior. Further research that takes the educational level into account is warranted, with regard to: (a) the family itself, (b) the processes within the family system, and (c) the effects of one family member on the family system. 
The above results are consistent with findings that emphasize that the family is an important social environmental context that shapes the individual's health behavior (Ball \& Timperio, 2006; La Guardia \& Patrick, 2014). Therefore, taking into account such an interindividual perspective could enrich research into health behavior.

\section{Limitations and Conclusions}

In this study, we assumed one direction of influence. However, the theoretical framework implies reciprocal interactions. The other direction, health behavior affecting perceived stress, may be significant as well. To verify directions, longitudinal studies with a cross-lagged-panel design would be necessary.

Parents and children report significantly more stress in all subscales than the scalespecific reference groups. Various factors might play a role. The reference values are from the year 2003 for parents and 2009 for children; the significant differences in the stress report indicate a change in the perception of stress during the last few years. For parents, stress seems to have increased during the last few years (Cohen \& Janicki-Deverts, 2012). For children the increase in the perception of stress may be a result of school reforms in the German school system. Perceived stress and health behavior were considered as stable parameters. However, these variables may change depending on the specific boundary conditions. Thus it would be interesting to investigate, perhaps with a day-to-day diary study, intra-individual short-term variations in stress perception and their effects on health behavior.

The relationship between one person's perceived stress and someone else's health behavior is more complex than assumed in this study (De Vriendt, Moreno, \& De Henauw, 2009). Including individual and family-level mediators and moderators, such as individual habits and attitudes, and the Family Health Climate (Niermann, Krapf, Renner, Reiner, \& Woll, 2014), would be beneficial to further investigate with this new perspective of linking perceived stress with family environment and the health behavior of other family members.

To the best of our knowledge, this is the first study to link perceived stress with health behavior on the individual level as well as between individuals within a family. Bandura's social cognitive theory (Bandura, 1989) and its expansion to the family level by Baranowski (1997) and Taylor, Baranowski, and Sallis (1994) represents a useful theoretical framework for describing inter-individual relationships between stress and health behavior within a family. Further research within this framework is necessary to gain more insight into the interactions between individuals and environment and to develop a testable theoretical model.

The results of our study indicate that individually perceived stress is related to individual health behavior as well as the health behavior of other family members. Furthermore, the results emphasize the importance of distinguishing between different health behaviors - such as core and non-core food consumption, and physical activity and sedentary behavior - and different sources of stress: family, work or school, and personal conflicts. The consideration of the family environment, including other family members, enriches previous results and adds a new perspective on the link between stress and health behavior. More insight into the interaction between individuals and their shared environment is important for the development of intervention programs. Above all, interventions that aim to improve the health behavior of children and adolescents should integrate the family, and should aim to improve family-level variables such as the Family Health Climate (Niermann et al., 2014). 


\section{References}

Adkins, C. L., \& Premeaux, S. F. (2012). Spending time: The impact of hours worked on work-family conflict. Journal of Vocational Behavior, 80(2), 380-389. http://dx.doi.org/10.1016/j.jvb.2011.09.003

Aldana, S. G., Sutton, L. D., Jacobson, B. H., \& Quirk, M. G. (1996). Relationship between leisure time physical activity and perceived stress. Perceptual and Motor Skills, 82(1), 315-321. http://dx.doi.org/10.2466/pms.1996.82.1.315

Azizi, M. (2011). Effects of doing physical exercises on stress-coping strategies and the intensity of the stress experienced by university students in Zabol, Southeastern Iran. Procedia - Social and Behavioral Sciences, 30(1), 372-375. http://dx.doi.org/10.1016/j.sbspro.2011.10.073

Balantekin, K. N., \& Roemmich, J. N. (2012). Children's coping after psychological stress. Choices among food, physical activity, and television. Appetite, 59(2), 298-304. http://dx.doi.org/10.1016/j.appet.2012.05.016

Ball, K., \& Timperio, A. (2006). Understanding environmental influences on nutrition and physical activity behaviors: where should we look and what should we count? International Journal of Behavioral Nutrition and Physical Activity, 3, 33-42.

Bandura, A. (1989). Social cognitive theory. In R. Vasta (Ed.), Annals of child development Vol. 6: Six theories of child development (pp. 1-60). Greenwich, CT: JAI Press.

Baranowski, T. (1997). Family and health actions. In D. S. Gochman (Ed.), Handbook of behavior research - Book 1: Personal and social determinants (Vol. 1, pp. 179-206). New York: Plenum Press.

Baranowski, T., Perry, C. L., \& Parcel, G. S. (1996). How individuals, environments, and health behavior interact: Social cognitive theory. In K. Glanz, F. M. Lewis, \& B. K. Rimer (Eds.), Health behavior and health education. Theory, research, and practice (2nd ed., pp. 153-178). San Francisco: Jossey-Bass.

Bauer, K. W., Hearst, M. O., Escoto, K., Berge, J. M., \& Neumarck-Sztainer, D. (2012). Parental employment and work-family stress: Associations with family food environments. Social Science and Medicine, 75(3), 496-504. http://dx.doi.org/10.1016/j.socscimed.2012.03.026

Bauer, K. W., Neumark-Sztainer, D., Fulkerson, J. A., Hannan, P. J., \& Story, M. (2011). Familial correlates of adolescent girls' physical activity, television use, dietary intake, weight, and body composition. International Journal of Behavioral Nutrition and Physical Activity, 8(1), 25-35. http://dx.doi.org/10.1186/1479-5868-8-25

Baum, A., Garofalo, J. P., \& Yali, A. M.. (2006). Socioeconomic status and chronic stress. Does stress account for SES effects on health? Annals of the New York Academy of Sciences, 896(1), 131-144. http://dx.doi.org/10.1111/j.1749-6632.1999.tb08111.x

Baumeister, R. F., Bratslavsky, E., Muraven, M., \& Tice, D. M. (1998). Ego deplemention: Is the active self a limited resource? Journal of Personality and Social Psychology, 74(5), 1252-1265. http://dx.doi.org/10.1037//0022-3514.74.5.1252 
Baxter, J. (2000). The joys and justice of housework. Sociology, 34(3), 609-631. http://dx.doi.org/10.1177/s0038038500000389

Beagan, B., Chapman, G. E., D'Sylva, A., \& Bassett, B. R. (2008). 'It's just easier for me to do it': Rationalizing the family division of foodwork. Sociology, 42(4), 651-671. http://dx.doi.org/10.1177/0038038508091621

Beaujot, R., \& Andersen, R. (2007). Time-crunch: Impact of time spent in paid and unpaid work and its division in families. Canadian Journal of Sociology, 32(3), 295-316. http://dx.doi.org/10.2307/20460645

Beets, M. W., Cardinal, B. J., \& Alderman, B. L. (2010). Parental social support and the physical activity-related behaviors of youth: a review. Health Education \& Behavavior, 37(5), 621-644. http://dx.doi.org/10.1177/1090198110363884

Bell, A. C., Kremer, P. J., Magarey, A. M., \& Swinburn, B. A. (2005). Contribution of 'noncore' foods and beverages to the energy intake and weight status of Australian children. European Journal of Clinical Nutrition, 59(5), 639-645. http://dx.doi.org/10.1038/sj.ejcn.1602091

Bevan, A. L., \& Reilly, S. M. (2011). Mothers' efforts to promote healthy nutrition and physical activity for their preschool children. Journal of Pediatric Nursing, 26(5), 395-403. http://dx.doi.org/10.1016/j.pedn.2010.11.008

Campbell, K., \& Crawford, D. (2001). Family food environments as determinants of preschool-aged children's eating behaviors: Implications for obesity prevention policy - a review. Austrailian Journal of Nutrition Dietetics, 58(1), 19-25.

Cashel, K., \& Jeffreson, S. (1995). The core food groups: the scientific basis for developing nutrition education tools. Canberra: National Health and Medical Research Council, Commonwealth of Australia.

Chen, Y., \& Li, H. (2009). Mother's education and child health: Is there a nurturing effect? Journal of Health Economics, 28(2), 413-426. http://dx.doi.org/10.1016/j.jhealeco.2008.10.005

Chomistek, A. K., Manson, J. E., Stefanick, M. L., Lu, B., Sands-Lincoln, M., Going, S. B., ... Eaton, C. B. (2013). Relationship of sedentary behavior and physical activity to incident cardiovascular disease: Results from the Women's Health Initiative. Journal of American College of Cardiology, 61(23), 2346-2354. http://dx.doi.org/10.1016/j.jacc.2013.03.031

Cohen, S., \& Janicki-Deverts, D. (2012). Who's stressed? Distributions of psychological stress in the United States in probability samples from 1983, 2006, and 2009. Journal of Applied Social Psychology, 42(6), 1320-1334. http://dx.doi.org/10.1111/j.1559-1816.2012.00900.x

Cutler, D. M., \& Lleras-Muney, A. (2010). Understanding differences in health behaviors by education. Journal of Health Economics, 29, 1-28. http://dx.doi.org/10.1016/i.jhealeco.2009.10.003

De Vriendt, T., Moreno, L. A., \& De Henauw, S. (2009). Chronic stress and obesity in adolescents: Scientific evidence and methodological issues for epidemiological research. Nutrition, Metabolism and Cardiovascular Diseases, 19(7), 511-519. http://dx.doi.org/10.1016/j.numecd.2009.02.009 
Deutsche Gesellschaft für Psychologie, \& Berufsverband Deutscher Psychologinnen und Psychologen. (2005). Ethische Richtlinien der Deutschen Gesellschaft für Psychologie e.V. und des Berufsverbandes Deutscher Psychologinnen und Psychologen e.V. [Ethical Guidelines of the German Society for Psychology Association and the Professional Association of German Psychologists]. Berlin: Berufsverband Deutscher Psychologinnen und Psychologen e.V.

Devine, C. M., Connors, M. M., Sobal, J., \& Bisogni, C. A. (2003). Sandwiching it in: spillover of work onto food choices and family roles in low- and moderate-income urban households. Social Science and Medicine, 56(3), 617-630. http://dx.doi.org/10.1016/s0277-9536(02)00058-8

Dishman, R. K., Washburn, R. A., \& Heath, G. W. (2004). Physical activity epidemiology. Champaign, IL: Human Kinetics.

German Nutrition Society (Producer). (2013). Vollwertig essen und trinken nach den 10 Regeln der DGE (Healthy nutrition - 10 rules of the DGE) Retrieved from http://www.dge.de/modules.php?name=Content\&pa=showpage\&pid=15

Godin, G., \& Shephard, R. J. (1997, June). Godin leisure-time exercise questionnaire. Medicine \& Science in Sports \& Exercise, 29(Supplement), S36-S38. http://dx.doi.org/10.1097/00005768-199706001-00009

Groesz, L. M., McCoy, S., Carl, J., Saslow, L., Stewart, J., Adler, N., ... Epel, E. S. (2011). What is eating you: Stress and drive to eat. Appetite, 58(2), 717-721. http://dx.doi.org/10.1016/j.appet.2011.11.028

HBSC Team Germany. (2011a). Studie Health Behaviour in School-aged Children Faktenblatt „Nutzung von Computer und Spielkonsole durch Kinder und Jugendliche [A study of health behavior in school-aged children - Facts about "the use of PC and games console of children and adolescents]. Bielefeld: WHO Collaborating Centre for Child and Adolescent Health Promotion.

HBSC Team Germany. (2011b). Studie Health Behaviour in School-aged Children Faktenblatt „Fernsehkonsum an Schultagen von Kindern und Jugendlichen [A study of health behavior in school-aged children - Facts about TV use on schooldays of children and adolescents]. Bielefeld: WHO Collabo-rating Centre for Child and Adolescent Health Promotion.

Heikkilä, K., Fransson, E. I., Nyberg, S. T., Zins, M., Westerlund, H., Westerholm, P., ... Kivimäki, M. (2013). Job strain and health-related lifestyle: Findings from an individual-participant meta-analysis of 118,000 working adults. American Journal of Public Health, 103(11), 2090-2097. http://dx.doi.org/10.2105/ajph.2012.301090

Hoover-Dempsey, K. V., Battiato, A. C., Walker, J. M. T., Reed, R. P., DeJong, J. M., \& Jones, K. P. (2001). Parental involvement in homework. Educational Psychologist, 36(3), 195-209. http://dx.doi.org/10.1207/s15326985ep3603_5

Jabs, J., Devine, C. M., Bisogni, C. A., Farrell, M., Jastran, M., \& Wethington, E. (2007). Trying to find the quickest way: Employed mothers' construction of time for food. Journal of Nutrition Education and Behavior, 39(1), 18-25. http://dx.doi.org/10.1016/j.jneb.2006.08.011 
Johansson, G., Johnson, J. V., \& Hall, E. M. (1991). Smoking and sedentary behavior as related to work organization. Social Science \& Medicine, 32(7), 837-846. http://dx.doi.org/10.1016/0277-9536(91)90310-9

Johnson, L., van Jaarsveld, C. H., \& Wardle, J. (2011). Individual and family environment correlates differ for consumption of core and non-core foods in children. British Journal of Nutrition, 105(6), 950-959. http://dx.doi.org/10.1017/s0007114510004484

Kandiah, J., Yake, M., Jones, J., \& Meyer, M. (2006). Stress influences appetite and comfort food preferences in college women. Nutrition Research, 26(3), 118-123. http://dx.doi.org/10.1016/j.nutres.2005.11.010

Kolip, P., Klocke, A., Melzer, W., \& Ravens-Sieberer, U. (2013). Gesundheit und Gesundheitsverhalten im Geschlechtervergleich - Ergebnisse des WHOJugendgesundheitssurveys [Health and health behavior in the gender comparison Results of the WHO youth health survey "Health behavior in school-aged children"]. Weinheim: Bealtz Juventa.

Kouvonen, A., Kivikäki, M., Elovainio, M., Virtanen, M., Linna, A., \& Vahtera, J. (2005). Job strain and leisure-time physical activty in female and male public sector employees. Preventive Medicine, 41(2), 532-539. http://dx.doi.org/10.1016/j.ypmed.2005.01.004

Kouvonen, A., Vahtera, J., Oksanen, T., Pentti, J., Väänänen, A. K. P., Heponiemi, T., ... Kivimäki, M. (2013). Chronic workplace stress and insufficient physical activity: A cohort study. Occupational and Environmental Medicine, 70(1), 3-8. http://dx.doi.org/10.1136/oemed-2012-100808

La Guardia, J. G., \& Patrick, H. (2014). The influence of the social environment on health behavior. In N. Weinstein (Ed.), Human motivation and interpersonal relationships. Theory, research, and applications (pp. 299-316). Dordrecht, Heidelberg, New York, London: Springer. http://dx.doi.org/10.1007/978-94-017-8542-6_13

Lake, A. A., Hyland, R. M., Mathers, J. C., Rugg-Gunn, A. J., Wood, C. E., \& Adamson, A. J. (2006). Food shopping and preparation among the 30-somethings: whose job is it? (The ASH30 study). British Food Journal, 108(6), 475-486. http://dx.doi.org/10.1108/00070700610668441

Laugero, K. D., Falcon, L. M., \& Tucker, K. L. (2011). Relationship between perceived stress and dietary and activity patterns in older adults participating in the Boston Puerto Rican Health Study. Appetite, 56(1), 194-204. http://dx.doi.org/10.1016/j.appet.2010.11.001

Lundberg, U., \& Frankenhaeuser, M. (1999). Stress and workload of men and women in high-ranking positions. Journal of Occupational Health Psychology, 4(2), 142-151. http://dx.doi.org/10.1037/1076-8998.4.2.142

Martín-Fernández, S., de los Ríos, I., Cazorla, A., \& Martínez-Falero, E. (2009). Pilot study on the influence of stress caused by the need to combine work and family on occupational accidents in working women. Safety Science, 47(2), 192-198. http://dx.doi.org/10.1016/j.ssci.2008.03.003

McAlister, A. L., Perry, C. L., \& Parcel, G. S. (2008). How individuals, environments, and health behavior interact: Social cognitive theory. In K. Glanz, B. K. Rimer \& K. Viswanath (Eds.), Health behavior and health education: Theory, research, and practice (Vol. 4, pp. 167-188). San Francisco: Jossey-Bass. 
International Journal of Child, Youth and Family Studies (2015) 6(1): 68-92

Michels, N., Sioen, I., Brae, C., Eiben, G., Hebestreit, A., Huybrechts, I., ... De Henauw, S. (2012). Stress, emotional eating behavior and dietary patterns in children. Appetite, 59(3), 762-769. http://dx.doi.org/10.1016/j.appet.2012.08.010

Mouchacca, J., Abbott, G. R., \& Ball, K. (2013). Associations between psychological stress, eating, physical activity, sedentary behaviors and body weight among women: a longitudinal study. BMC Public Health, 13, 828. http://dx.doi.org/10.1186/1471-2458-13-828

Muraven, M., \& Baumeister, R. F. (2000). Self-regulation and depletion of limited resources: Does self-control resemble a muscle? Psychological Bulletin, 126(2), 247-259. http://dx.doi.org/10.1037//0033-2909.126.2.247

Ng, D. M., \& Jeffrey, R. W. (2003). Relationships between perceived stress and health behaviors in an sample of working adults. Health Psychology, 22(6), 638-642. doi: 10.1037/0278-6133.22.6.638

Niermann, C., Krapf, F., Renner, B., Reiner, M., \& Woll, A. (2014). Family health climate scale (FHC-scale): development and validation. International Journal of Behavioral Nutrition and Physical Activity, 11, 30. http://dx.doi.org/10.1186/1479-5868-11-30

Oliver, G., \& Wardle, J. (1999). Perceived effects of stress and food choice. Physiology \& Behavior, 66(3), 511-515. http://dx.doi.org/10.1016/s0031-9384(98)00322-9

Park, C. L., \& Iacocca, M. O. (2014). A stress and coping perspective on health behaviors: Theoretical and methodological considerations. Anxiety, Stress and Coping, 27(2), 123-137. http://dx.doi.org/10.1080/10615806.2013.860969

Petrowski, K., Paul, S., Albani, C., \& Brähler, E.. (2012). Factor structure and psychometric properties of the trier inventory for chronic stress (TICS) in a representative German sample. BMC Medical Research Methodology, 12, 42-52. http://dx.doi.org/10.1186/1471-2288-12-42

Prochaska, J. J., Sallis, J. F., \& Long, B. (2001). A physical activity screening measure for use with adolescents in primary care. Archives of Prediatric Adolescence Medicine, 155(5), 554-559. http://dx.doi.org/10.1001/archpedi.155.5.554

Proper, K. I., Singh, A. S., van Mechelen, W., \& Chinapaw, M. J. (2011). Sedentary behaviors and health outcomes among adults. A systematic review of prospective studies. American Journal of Preventive Medicine, 40(2), 174-182. http://dx.doi.org/10.1016/j.amepre.2010.10.015

Reis, H. T., Collins, W. A., \& Berscheid, E. (2000). The relationship context of human behavior and development. Psychological Bulletin, 126(6), 844-872. http://dx.doi.org/10.1037//0033-2909.126.6.844

Repetti, R., Wang, S., \& Saxbe, D. (2009). Bringing it all back home: How outside stressors shape families' everyday lives. Current Directions in Psychological Science, 18(2), 106-111. http://dx.doi.org/10.1111/j.1467-8721.2009.01618.x 
Richartz, A., Hoffmann, K., \& Sallen, J. (2009). Skalen zum chronischen Stress im Kindesalter (CSiK) Kinder im Leistungssport - Chronische Belastungen und protektive Ressourcen [Scales for chronic stress in childhood. Children in professional sports - Chronic strain and protective resources] (pp. 77-80; 334-338). Schorndorf: Hofmann.

Roemmich, J. N., Lambiase, M. J., Lobarinas, C. I., \& Balantekin, K. N. (2011). Interactive effects of dietary restraint and adiposity on stress-induced eating and the food choice of children. Eating Behaviors, 12(4), 309-312. http://dx.doi.org/10.1016/j.eatbeh.2011.07.003

Rostad, F. G., \& Long, B. C. (1996). Exercise as a coping strategy for stress: a review. International Journal of Sport Psychology, 27(2), 197-222.

Schulz, P., Schlotz, W., \& Becker, P. (2004). Trierer Inventar zum chronischen Stress (Tics).(Trier Inventory of Chronic Stress (Tics).) Göttingen, Germany: Hogrefe.

Steptoe, A. (2007). Health behavior and stress. In G. Fink (Ed.), Encyclopedia of stress. (pp. 262-266). San Diego, CA: Academic Press.

Stults-Kolehmainen, M., \& Sinha, R. (2014). The effects of stress on physical activity and exercise: A systematic review. Sports Medicine, 44(1), 81-121. http://dx.doi.org/10.1007/s40279-013-0090-5

Taylor, W. C., Baranowski, T., \& Sallis, J. F. (1994). Family determinants of childhood physical activity: A social - cognitive model. In R. K. Dishman (Ed.), Advances in exercise adherence. Champaign, IL: Human Kinetics.

Tinsley, B. J. (1997). Maternal influences on children's health behavior. In D. S. Gochman (Ed.), Handbook of behavior research - Book 1: Personal and social determinants (Vol. 1, pp. 223-240). New York: Plenum Press.

Torres, S., \& Nowson, C. (2007). Relationship between stress, eating behavior, and obesity. Nutrition, 23(11/12), 887-894. http://dx.doi.org/10.1016/j.nut.2007.08.008

Tryon, M. S., DeCant, R., \& Laugero, K. D. (2013). Having your cake and eating it too: A habit of comfort food may link chronic social stress exposure and acute stress-induced cortisol hyporesponsiveness. Physiology \& Behavior, 114/115, 32-37. http://dx.doi.org/10.1016/j.physbeh.2013.02.018

Wallis, D. J., \& Hetherington, M. M. (2009). Emotions and eating. Self-reported and experimentally induced changes in food intake under stress. Appetite, 52(2), 355-362. http://dx.doi.org/10.1016/j.appet.2008.11.007

Wardle, J., Haase, A. M., Steptoe, A., Nillapun, M., Jonwutiwes, K., \& Bellissle, F. (2004). Gender differences in food choice: The contribution of health beliefs and dieting. Annals of Behavioral Medicine, 27(2), 107-116. http://dx.doi.org/10.1207/s15324796abm2702_5

Wardle, J., Steptoe, A., Oliver, G., \& Lipsey, Z. (2000). Stress dietary restraint and food intake. Journal of Psychosomatic Research, 48(2), 195-202. http://dx.doi.org/10.1016/s0022-3999(00)00076-3

Westman, M., \& Etzion, D. (2005). The crossover of work-family conflict from one spouse to the other. Journal of Applied Psychology, 35(9), 1936-1957. http://dx.doi.org/10.1111/j.1559-1816.2005.tb02203.x 
International Journal of Child, Youth and Family Studies (2015) 6(1): 68-92

Wijndaele, K., Matton, L., Duvigneaud, N., Lefevre, J., De Bourdeaudhuij, I., Duquet, W., ... Philippaerts, R. M. (2007). Association between leisure time physical activity and stress, social support and coping: A cluster-analytical approach. Psychology of Sport and Exercise, 8(4), 425-440. http://dx.doi.org/10.1016/j.psychsport.2006.08.001

Winkler, G., \& Döring, A. (1998). Validation of a short qualitative food frequency list used in several German large scale surveys. Zeitschrift für Ernährungswissenschaft, 37, 234-241. http://dx.doi.org/10.1007/p100007377

World Health Organization. (2010). Global recommendations on physical activity for health. Geneva, Switzerland: WHO Press.

Zellner, D. A., Loaiza, S., Gonzalez, Z., Pita, J., Morales, J., Pecora, D., \& Wolf, A. (2006). Food selection changes under stress. Physiology \& Behavior, 87(4), 789-793. http://dx.doi.org/10.1016/j.physbeh.2006.01.014

Zellner, D. A., Saito, S., \& Gonzales, J. (2007). The effect of stress on men's food selection. Appetite, 49(3), 696-699. http://dx.doi.org/10.1016/j.appet.2007.06.013 